\title{
CONTROVERSY ABOUT THE ANALYSIS OF COMPLAINTS RECEIVED IN THE PROFESSIONAL ETHICS COMMITTEES OF THE BULGARIAN MEDICAL ASSOCIATION
}

\author{
Juliana Marinova $^{1}$, Chubrina Racheva ${ }^{2}$, Krum Marinov $^{3}$, Boryana Parashkevova ${ }^{1}$ \\ ${ }^{1}$ Department of Social Medicine and Health Care Management, \\ Medical Faculty, Trakia University, Stara Zagora \\ ${ }^{2}$ External Consultant, Trakia Univesrsity \\ ${ }^{3}$ Student of Medicine, Medical Faculty, Trakia University, Stara Zagora
}

\section{ABSTRACT}

The ethical challenges of the health care reform largely reflect on physicians, patients and society.

The purpose of this paper is to pose the question about the applicability of a summary analysis of complaints filed to the Professional Ethics Committees of the Bulgarian Medical Association, towards contributing to the identification of problems and possible solutions for the improvement of the situation in the healthcare system and highlighting the role of the medical professional organization in this process.

MATERIALS AND METHODS: We present our experience in the ethical analysis of complaints received in the Professional Ethics Committee at the Bulgarian Medical Association, Stara Zagora for the periods 2007-2010 and 2011-2014. Qualitative content analysis of the documents was applied. Cases described in the complaints are analyzed using a specifically designed questionnaire.

RESULTS AND DISCUSSION: In most cases, the authors of the complaints describe conflicts of various dimensions of medical care quality as the most highlighted cases are ones related to the access to timely and specialized medical care, as well as the adequacy of the diagnostic and therapeutic procedures and achieved results of the treatment process. The problems that emerged reflect the ethical conflicts in the health care system associated with limited access and doctor-patient ailing trust.

CONCLUSION: Considering the strengths and weaknesses of the applied methodology, the highly subjective interpretation of the issues presented in the perspective of different people, as well as the manner in which this analysis is provided we raise the following issue: how appropriate is for professional ethics committees to carry out such analysis?

Keywords: Professional Ethics Committee, Medical Association, qualitative content analysis of complaints, ethical conflicts

Address for correspondence:

Juliana Marinova

Department of Social Medicine and Health Care

Management

Medical Faculty, Trakia University, Stara Zagora

11 Armeiska Street,

6000 Stara Zagora, Bulgaria

e-mail: marinova@mf.uni-sz.bg

Received: January 22, 2016

Accepted: April 11, 2016

\section{INTRODUCTION}

The ethical challenges of the health care reform largely reflect on physicians, patients and society. The topic "medical errors" is placed on the agenda as a problem of the entire health system with its multiple dimensions: medical, economic, legal, ethical ones. These are problems of the whole society, especially in the field of social and health policy and the focus should not be placed only on the medical 
Juliana Marinova, Chubrina Racheva, Krum Marinov et al.

error itself $(1,2)$. As an equal member of the European Union our country, the Republic of Bulgaria, should have a health system that guarantees a high level of human health protection and enables the implementation of a health policy which respects patients' rights according to and as stated in official documents of the European Union: Second Program of Community Action in the Field of Health (20082013), Common Values and Principles in European Union Health Systems (2006/C 146/01), Opinion of the European Economic and Social Committee on “Patients' Rights' $(3,4,5)$.

The purpose of this paper is to pose the question about the applicability of a summary analysis of complaints, filed to the Professional Ethics Committees of the Bulgarian Medical Association, for the identification of problems and possible solutions with the aim of improving the situation in the healthcare system and highlighting the role of the medical professional organization in this process.

Materials and Methods: We present our experience in the ethical analysis of complaints received in the Professional Ethics Committee of the Bulgarian Medical Association, Stara Zagora for the period 2007-2010 (56 complaints) (6) and for the period 2011-2014 (58 complaints). Qualitative content analysis of the documents was applied. Cases described in the complaints are analyzed using a self-administered questionnaire designed specifically for the study. During the content analysis we applied a complex approach applying different techniques so that we could express the complainant's view point as well as categorize the document in a certain way through interpreting it according to the modern ideas about patient's rights $(7,8)$.

In relation to the specificities of the applied method of qualitative analysis important circumstances that we should highlight are:

1. The problems are defined as ethical and have to be resolved by an ethical committee;

2. They reflect the complainant's view point;

3. They reflect the interpretations of the researchers in analyzing the content.

\section{RESULTS AND DISCUSSION}

Results from the analysis of the period 2007 -2010 (6):
* Basic characteristics of the authors of the complaints (complainants) - demographic and social as far as we can get an idea about that from the documents. The relative percentage of complaints written by women is higher (30 documents, 53.6\%). The majority of complainants are urban dwellers $76 \%$, which corresponds to the profile of the population in the region.

* Almost $77 \%$ of the complaints are filed by patients or their relatives. The number of complaints filed by physicians - members of the professional organization are 11: almost every fifth complaint.

* The number of the filed complaints is increasing during the described period: from 12 in 2007 to 17 in 2010.

* Ways of filing the complaints for consideration in the Professional Ethics Committee: 30(53.6\%) of the complaints are forwarded to the PEC by other institutions (Ministry of Health, Regional Centre for Healthcare, National Health Fund and others) for competent consideration. The rest of the complaints are filed directly in the PEC and here we note that in most of the cases they are also addressed to the institutions stated above.

* In the majority of complaint we can find a clearly stated demand or a clearly asked and unambiguous question: 49 (87.5\%). In these documents the view point of the complainant toward the problem is reflected and we are able to describe the ethical problem identified as such from the author of the complaint.

* The majority of the described complaints are belong to the system of the physician-patient relationship (physician-patient-patient's relatives) (41 complaints), but there are some that describe conflicts in the physician-physician system (9 complaints). Recently the count of such with discussion of the physician-society system of relations is also increasing. These are complaints that describe conflicts in the physician-patient relationship but interpret the problem in the context of its social aspects and reflections.

* The identification of the ethical problems raised in the complaints is based on the approach of 
affirming the patient's rights which are systematized according to the separate levels of healthcare. They are distributed almost evenly between general medical practice (14 complaints), specialized outpatient care (14 complaints), hospital care (15 complaints). Problems of the emergency medical care and such of coordination between the different levels of healthcare are discussed in the other complaints.

* In most cases the authors of the complaints describe conflicts connected to different dimensions of the quality of healthcare $(47 \mathrm{com}-$ plaints - 84\%) as those connected to the access to prompt and specialized healthcare as well as adequacy of the used diagnostic and therapeutic procedures ( 24 cases $-51 \%$ ) are in first place. The next group is connected to violated rights in the context of unfavorable results - inflicted harm as a result of medical care: this is the message of $22(39.3 \%)$ of the complaints, 8 of which describe a fatal outcome.

* Most of the complaints related to the physicianpatient relationship system stated above refer to problems with care for adult competent patients (29 complaints - 70\% in this system of relationships). Problems connected to medical service for children are stated in 11 complaints.

* The used expressions and words in the analyzed complaints are related to:

* Ethical behavior in the diagnostic and treatment process (27 complaints): responsibility, timeliness, adequacy, consequences and complications of the applied therapy; untimely and inadequate actions taken, idleness or refusal of treatment. We can also encounter terms such as "negligence" and "impunity", "murderous therapy". In these complaints we also often encounter the terms "justice" along with "responsibility" or "irresponsibility" and "retribution".

* Problems of the healthcare system and their reflection on patients and the physician society (15 complaints): "damaging the prestige of the medical profession", "serious violation of the patient's freedom of choice and mutual trust and respect between the physician and the patient". The term "health genocide" is used in two of the complaints: e.g. "Our timely inter- ference instead of helping is sending the people faster to the beyond - this is health genocide!" or: "Where has our medicine gone to? I experienced injustice at our hospital."

* Aspects of the interpersonal communication physician-patient-relatives of the patient (10 complaints): rude behavior, neglect, abuse of trust, deception, lie, insufficient or no information. We encounter words and expressions such as "liars", "quality lying", "brutal behavior", "doctors without ethics and morality".

The discussion of the results depends on various and differently interpreted circumstances, attitudes of people, demands, understanding of their rights and expectations (patient preferences).

In most cases, the authors of the complaints describe conflicts of various dimensions of quality of care as the most highlighted cases are ones related to the access to timely and specialized medical care, as well as the adequacy of the diagnostic and therapeutic procedures and achieved results of the treatment process. The problems that emerged reflect the ethical conflicts in the health care system associated with limited access and doctor-patient ailing trust.

Discussion on the controversy of the analysis of complaints received in Professional Ethics Committees: How appropriate is it for professional ethics committees to carry out such analysis?

Considering the strengths and weaknesses of the applied methodology, the highly subjective interpretation of the issues presented from the perspective of different people, as well as the manner in which this analysis is carried out we raise the issue for debate: how appropriate is it for professional ethics committees to carry out such analysis?

Does this analysis enrich the evidence justifying certain changes in the healthcare system?

Should professional ethics committees deal with this?

Are the analyses of the medical audit (such as these of the Executive Agency for Medical Audit) sufficient?

Isn't it an expression of self-respect and merit for the self-regulating professional organization to carry out such analysis?

We also pose the question "Who is the addressee of such analysis?". 
Juliana Marinova, Chubrina Racheva, Krum Marinov et al.

How can the results of the analysis influence policy and management, so as to contribute to the encouragement of good practices in respect of the rights, interests and needs of all participants in the medical care system?

\section{CONCLUSION}

In this article we present our experience with the ethical analysis of complaints and a methodological approach for providing evidence in support of adequate health policies and decisions (evidencebased). We raise questions about the controversy of this analysis carried out by the regional ethics committees of the Bulgarian Medical Association.

\section{Notes}

This material was presented as a poster presentation at the UNESCO World Conference BIOETHICS, MEDICAL ETHICS \& HEALTH LAW, October 20-22, 2015, Naples, Italy.

\section{Acknowledgements}

The authors express their gratitude to Assoc. Prof. Zdravka Toneva, MD, PhD for the methodological consultation and Dr. Georgi Bakoev - Chairman of Regional Medical Association - Stara Zagora.

\section{REFERENCES}

1. Petrova Zl., One year activity of Executive Agency for Medical Audit - results and problems, Medical Meridians, 2, 2011: 21-26. (in Bulgarian)

2. Popova M., Medical Errors - Personal Fault or Problem of the Management, available from: http:// www.eama.bg/uploads/file/medicinski_greshki.pdf (in Bulgarian)

3. Decision № 1350/2007 / of the European Parliament and of the Council of 23 October 2007 establishing a second program of Community action in the field of health (2008-2013), the Official Journal of the European Union, 20.11.2007.

4. Council Conclusions on Common values and principles in European Union Health Systems (2006/C $146 / 01)$, Official Journal of the European Union, 22.6.2006.

5. Opinion of the European Economic and Social Committee on "Patients' rights', (2008/C 10/18), Official Journal of the European Union, 15.1.2008.

6. Marinova J., B. Parashkevova, Sv. Dimitrova, G. Chamova, G. Petrova, Content Analysis of Complaints Filed in the Professional Ethics Commit- tee of Regional Professional Organisation of Physicians in Stara Zagora - Reflection of Ethical Problems Existing in the Period of Bulgarian Healthcare Reform, Social Medicine, 2, 2013: 18-20. (in Bulgarian)

7. Svetlana Saykova, Atanas Atanasov, Emilia Chengelova, Social Survey research, Methodological aspects, Sofia, 2014, Prof. Marin Drinov Academic Publishing House, 394.

8. Carol Busch, Paul S. De Maret, Teresa Flynn, Rachel Kellum, Sheri Le, Brad Meyers, Matt Saunders, Robert White, and Mike Palmquist. (1994 - 2012). Content Analysis. Writing@CSU. Colorado State University. Available from: http://writing.colostate. edu/guides/guide.cfm?guideid=61. 